\title{
DA ÉTICA DOS PCNs À ÉTICA DA SALA DE AULA
}

\author{
CAPELA, Rita Josélia da - UERJ ${ }^{1}$ \\ NAZAR, Terezinha Regina Nogueira - UERJ ${ }^{2}$ \\ "LIBERDADE, essa palavra que o sonho humano alimenta, \\ que não há ninguém que explique, \\ e ninguém que não entenda..." \\ Cecilia Meireles
}

\section{RESUMO:}

Este trabalho tem como objetivo oferecer aos professores da Educação Básica uma abordagem diferente da desenvolvida na sala de aula tradicional. Abordagem essa, em que os alunos possam desenvolver seus próprios meios e recursos de aprendizado de valores, descobrindo e vivenciando competências e habilidades. Propõe-se uma reflexão a partir da fundamentação teórica da ética dos PCNs até a prática vivenciada nas salas de aulas, por alunos e professores, para que o espírito crítico, efetivamente, seja incorporado ao cotidiano dos indivíduos como um "saber ser" e "saber fazer". A partir da problematização da realidade que cerca o aluno e o fazer pedagógico que norteia a prática no cotidiano das salas de aula, buscar-se-á propiciar vivências que favoreçam o repensar da valorização da dimensão ética, propriamente dita, como uma ênfase para além da racionalidade, na sensibilidade e afetividade, na formação para a vida e na direção da autonomia com responsabilidade. A abordagem da Filosofia proposta está baseada na superação do senso comum, enquanto interpretação da realidade, mostrando a filosofia como instrumental crítico para compreensão de si mesmo e do mundo, em seus múltiplos aspectos.

PalaVRas-Chave: Filosofia - Ética - Educação.

\begin{abstract}
:
The aim of the present work is to offer Basic Education teachers an approach to teaching that differs from the one developed in the traditional classroom. Through this new approach, the learning of values is facilitated by the development of the students' own means and learning

\footnotetext{
${ }^{1}$ Doutora em Filosofia: Filosofia Luso Brasileira pela UGF. Professora Associada da Universidade do Estado do Rio de Janeiro (UERJ). E-mail: ritacapela@ig.com.br

${ }^{2}$ Mestre em Educação: Representações Sociais e Práticas Educativas pela UNESA. Pedagoga da Universidade do Estado do Rio de Janeiro (UERJ). E-mail: terezinhanazar@globo.com
} 
resources, discovering and experiencing skills and abilities. The idea is to propose a reflection from the theoretical foundation of the ethics of the PCNs (Parâmetros Curriculares NacionaisNational Curricular Parameters) to the classroom praxes of students and teachers, so that the critical thinking is effectively incorporated into the daily life of individuals as a "knowledge": selfknowledge and know-how. From the questioning of reality that surrounds the pupil and the pedagogy that guides the daily routine in the classrooms, we seek to provide experiences that encourage the rethinking of the appreciation of the ethical dimension itself as an emphasis beyond rationality, sensitivity and affectivity in the formation for life, and in the direction of autonomy with responsibility. The philosophical approach proposed is based on the overcoming of the common sense as an instance of interpretation of reality, offering Philosophy as a critical instrument for the understanding of the self and the world in their multiple aspects.

KeYwords: Philosophy - Ethics - Education.

A nova Lei de Diretrizes e Bases - LDB - Lei n. 9394/96 (BRASIL, 1996), que regulamenta a educação no Brasil, deixa claro que a educação contemporânea é um trabaIho para todos, para que se construa uma sociedade mais justa, onde as diferenças não sejam negadas e sim reconhecidas e valorizadas dentro e fora das escolas.

Art. $1^{\circ}$. A educação abrange os processos formativos que se desenvolvem na vida familiar, na convivência humana, no trabalho, nas instituições de ensino e pesquisa, nos movimentos sociais e organizações da sociedade civil e nas manifestações culturais. (BRASIL, 1996)

A escola, cuja missão é promover a educação, muitas vezes reproduz o modelo das relações da sociedade onde as desigualdades sociais e o desrespeito às diferenças individuais se fazem presentes. De acordo com Bossa (2002, p.19), "no Brasil, a escola torna-se palco cada vez mais de fracassos e de formação precária, impedindo os jovens de se apossarem da herança cultural, dos conhecimentos acumulados pela humanidade e, consequentemente, de compreenderem melhor o mundo que os rodeia".

O fazer pedagógico é responsabilidade da escola. Assim sendo, a filosofia e metodologia, que permeiam sua "práxis", precisam estar pautadas nos princípios de liberdade, nos ideais de solidariedade humana e igualdade social para contribuir, efetivamente, na formação de seres sociais capazes de agir e interagir no meio circundante, para o exercício da cidadania.

Consideramos relevante trazer esta questão para a esfera do trabalho docente, para suscitarmos questões sobre o repensar o papel dos educadores que circulam no cotidiano escolar, como orientadores do processo de ensino e aprendizagem.

Deste modo, o objetivo da escola, de acordo com a Lei de Diretrizes e Bases e os Parâmetros Curriculares Nacionais (PCNs), vai além do ensino de conteúdos específicos. Visa à formação de cidadãos capazes de se articular em uma sociedade democrática.

Levando-se em conta as finalidades do Ensino Médio, descritas no artigo 35 da LDB 9034/96, destacamos os incisos III e IV: 


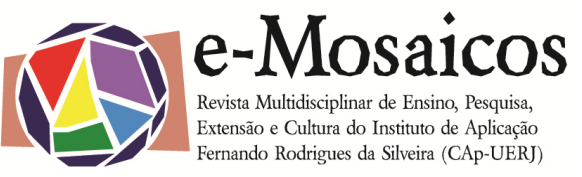

III - O aprimoramento do educando como pessoa humana, incluindo a formação ética e o desenvolvimento da autonomia intelectual e do pensamento crítico;

IV - A compreensão dos fundamentos científicos - tecnológicos dos processos produtivos, relacionando a teoria com a prática, no ensino de cada disciplina.

A análise destes incisos nos permite afirmar que a formação deste cidadão, entendido como pessoa capaz de fazer confluir a verdade, o bem e o belo, está relacionada ao ensino da Filosofia. Parece que voltamos ao ideal grego de redundância do belo à verdade bem aplicada.

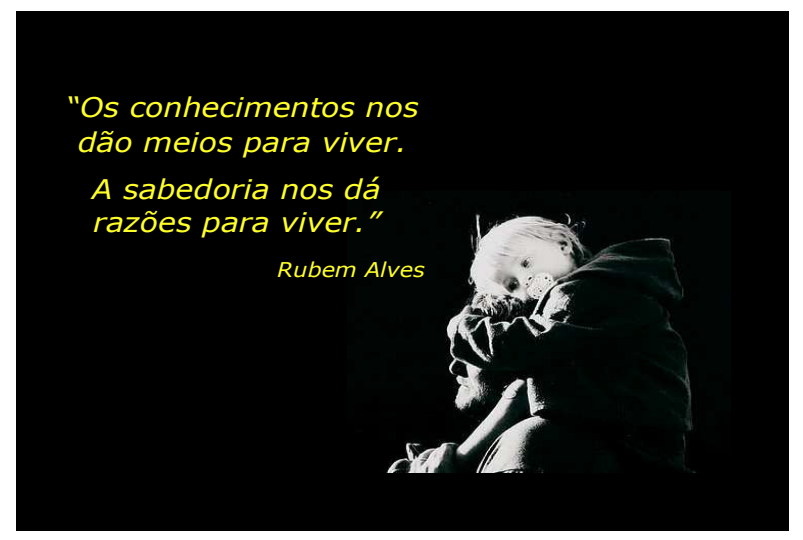

Fig. 1: Conhecimento x Sabedoria

Entretanto, sabemos que, na sociedade contemporânea, a crise de paradigmas que [des] orienta a existência humana, o estado de injustiça social e os problemas ambientais, enquanto fruto de certo modo humano ocidental de produzir cultura, de se apropriar de sua história e ocupar o espaço terrestre, estão presentes no cotidiano dos seres humanos e sociais, que agem e interagem em diferentes ambientes. Consequentemente, também chegam às escolas, uma vez que estas reproduzem o modelo desta sociedade, o que nos faz considerar que somente uma experiência pedagógica capaz de buscar, no interior da própria crise, soluções criativas que façam sentido para todos os envolvidos no processo vivenciado pelos diferentes atores sociais que circulam no ambiente escola, pode ser considerada eficaz.

Neste contexto, acreditamos que a retomada de cada ser humano, enquanto agente da História e de sua própria história, tendo como fim a vida comum, precisa ser vivenciada de modo integral e não mais fragmentada e para tal, se torna fundamental estimular na escola experiências com o conhecimento que favoreçam a tomada de consciência deste processo.

A valorização da dimensão ética, propriamente dita, pode ser compreendida como uma ênfase para além da racionalidade, na sensibilidade e afetividade, na formação do educando para a vida e na direção da autonomia com responsabilidade. Faz-se necessário que o ser humano construa criticamente seus significados, para uma existência mais justa e feliz, tendo cada vez mais uma vivência concreta e plena de sentido, a partir dos conhecimentos adquiridos. Contudo, acreditamos que ideias somente não conduzem o ser humano na direção de uma cultura de paz, mas sim uma disponibilidade interna que pode ser fomentada, levando em conta a sensibilidade, a criatividade e a racionalidade vivenciadas integralmente nas relações (consigo mesmo, interpessoais, com o conhecimento, com a natureza).

Entendemos ser necessário problematizar a realidade que cerca o nosso aluno adolescente, pois vivemos uma época onde se fala muito em falta de valores e imaturidade destes adolescentes. Entretanto, muito além do apontar tais deficiências, torna-se importante mostrar como estes adolescentes poderiam intuir um mergulho ao seu 
redor, permitindo uma interlocução deste ser humano-aluno com o mundo, que começaria com ele mesmo, a partir da compreensão de seus limites, da sua finitude e capacidade de transcendência, do conhecimento de suas necessidades de amor, respeito e compreensão.

Consideramos, também, que os fins da educação e da escola merecem ser examinados na perspectiva do homem como um ser no mundo, que se situa socialmente e historicamente e vive numa relação constituinte de si mesmo, consigo mesmo, com as coisas, com os outros e com o mundo.

Os PCNs do Ensino Médio trazem, como proposta, uma nova escola, com uma reorganização curricular em áreas de conhecimento onde as diferentes disciplinas se organizam e se articulam no interior de cada uma das áreas e no conjunto delas. O Ensino Médio perde sua antiga característica de preparatório para o ensino superior ou profissionalizante e assume um papel de terminalidade, pois passa a ser a etapa final da educação básica, onde o aluno será "sujeito produtor de conhecimento e participante do mundo do trabalho" (PARÂMETROS CURRICULARES NACIONAIS, 1999, p. 20).

Os princípios e fins explicitados na Lei de Diretrizes e Bases para a Educação Nacional exigem uma reforma curricular no Ensino Médio para esta nova escola e impõem a formulação de uma proposta pedagógica própria, onde habilidades e competências sejam desenvolvidas, dando continuidade ao processo de aquisição de conhecimentos adquiridos pelos seus diferentes sujeitos. Segundo Marchesi (2006, p. 165) existe

um amplo consenso no âmbito educacional de que atribuir às escolas maior capacidade de iniciativa e de decisão própria é um fator que contribui para melhorar a qualidade do ensino. É necessário lembrar que a autonomia das escolas não é um objetivo em si mesmo, mas um meio para se conseguir outras finalidades de maior importância: melhorar a qualidade e a equidade na educação.

Compreendemos a escola como facilitadora do processo de construção do conhecimento para a vida e da formação do sujeito humano e do cidadão. Sabemos que modelos prontos não existem, ou seja, as teorias sobre educação e suas práticas pedagógicas não fornecem aos professores manuais de instruções sobre o fazer pedagógico. Hoje, muito se fala em práticas pedagógicas neste espaço, e muitos significados estão associados a esta expressão, comumente quando discutimos este fazer pedagógico, competência do professor. Assim sendo, definimos práticas pedagógicas como o conjunto de ações, reflexões e procedimentos intencionais e educativos que se formalizam na instituição escola, tendo como objetivo favorecer a construção de conhecimentos, conceitos e valores dos alunos com a intermediação dos professores.

A educação ainda não está no rumo certo, falta a visão da necessidade de educar a sensibilidade, uma educação da sensibilidade é uma educação voltada para valores éticos - morais, estéticos, políticos, espirituais e democráticos. Educar para os tempos da pós-modernidade significa priorizar uma educação capaz de estimular a reflexão e a crítica, de forma que nossos jovens alunos saibam, efetivamente, como cultivar a ética, a transcendência, a cooperação, a solidariedade e o respeito à vida. 


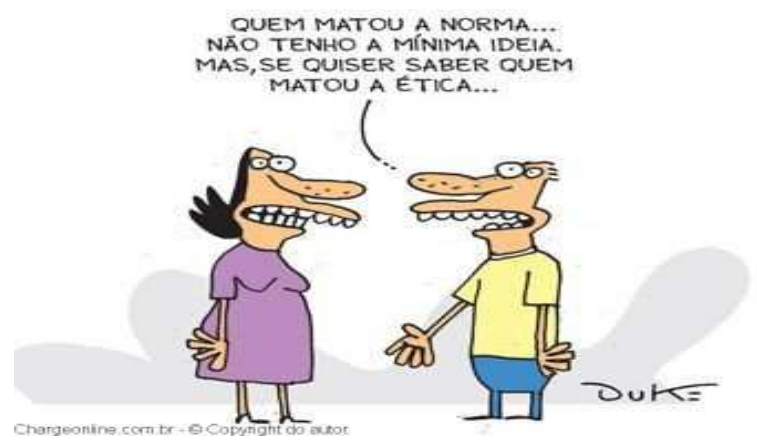

Fig. 2: Que Ética é esta?

Diante do cenário delineado, consideramos o diálogo fundamental para as relações que se estabelecem na escola e nas salas de aula entre alunos e professores, uma vez que entendemos que ambos serão aprendizes neste cotidiano escolar, partiIhando e compartilhando cada nova experiência vivenciada e ampliando saberes.

Segundo Tardif, a afinidade do educador com os saberes não é limitada a um papel de difusão de conhecimentos estabelecidos, pois, para ele, a prática do professor agrega diferentes saberes e mantém diferentes relações com eles. Para o autor, a epistemologia da prática profissional é "o estudo do conjunto dos saberes utilizado realmente pelos profissionais em seu espaço de trabalho cotidiano para desempenhar todas as suas tarefas" (TARDIF, 2002, p. 10). Isto quer dizer que a noção de "saber" junta informações científicas, capacidade, aptidão e os modos de agir no chamado saber fazer e saber ser.

Encontramos, nas orientações complementares aos PCNs (2002, p. 09), que os saberes dos alunos devem ser

mais do que reproduzir dados, denominar classificações ou identificar símbolos, estar formado para a vi$\mathrm{da}$, num mundo como o atual, de tão rápidas transformações e de tão difíceis contradições, significa saber se informar, se comunicar, argumentar, compreender e agir, enfrentar problemas de qualquer natureza, participar socialmente, de forma prática e solidária, ser capaz de elaborar críticas ou propostas e, especialmente, adquirir uma atitude de permanente aprendizado.

Tendo em vista que "Filosofar" é um fazer intrínseco ao ser humano, propomos discutir com os professores/educadores como transformar os questionamentos dos estudantes e os nossos próprios questionamentos em matéria-prima no cotidiano das salas de aula. É sabido que a Filosofia habita a vida de todos nós e, assim sendo, nossas ações, nossa conduta, nossas indagações e angústias passam a ser objetos privilegiados das discussões filosóficas, mais particularmente, de questionamentos éticos.

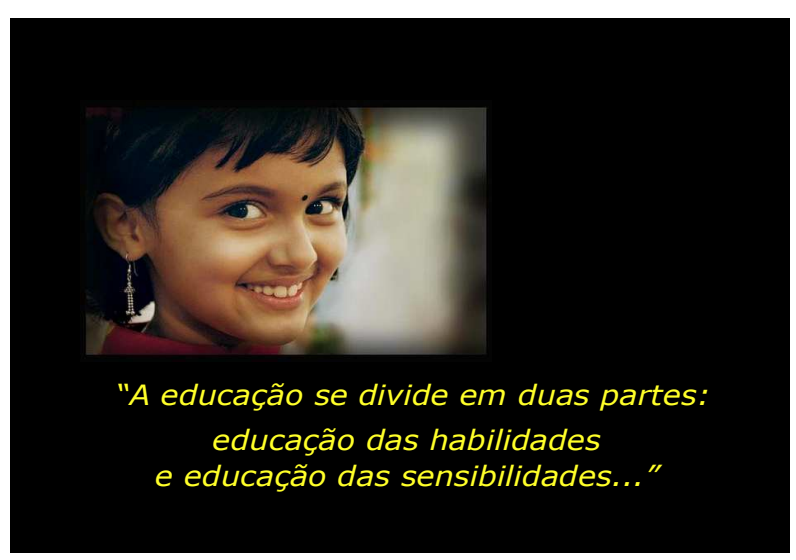

Fig. 3: Educação: para que e por quê?

A partir do pressuposto de que uma única definição de Filosofia estaria limitando o seu campo de ação, ou estaria Ihe conferindo especificidade incorreta, optamos por descrevê-la e abordá-la como um instrumento de análise, reflexão e crítica, que busca, por meio de diferentes leituras (perspectivas filosóficas), fundamentar e dar sentido à realidade, em seus múltiplos aspectos, quer sejam científicos, culturais, 
políticos ou históricos, conduzindo o aluno, no sentido de desenvolver um pensamento crítico e autônomo diante de tal realidade.

Nesse sentido, a abordagem da Filosofia, que este programa propõe, está baseada na superação do senso comum, enquanto interpretação da realidade, mostrando a filosofia como instrumental crítico para compreensão de si mesmo e do mundo, em seus múltiplos aspectos, representados através das diversas temáticas abordadas.

Utilizaremos, para nossas reflexões acerca de ética e moral, as palavras empregadas pelo professor Adolfo Sánchez Vásquez (2008, p. 12):

Não se podem confundir a ética e a moral. A ética não cria a moral. Conquanto seja certo que toda moral supõe determinados princípios, normas ou regras de comportamento, não é a ética que os estabelece numa determinada comunidade. A ética depara com uma experiência histórico-social no terreno da moral, ou seja, como uma série de práticas morais já em vigor e, partindo delas, procura determinar a essência da moral, sua origem, as condições objetivas e subjetivas do ato moral, as fontes da avaliação moral, a natureza e a função dos juízos morais, os critérios de justificação destes juízos e o princípio que rege a mudança e a sucessão de diferentes sistemas morais [...]. A ética não é a moral e, portanto, não pode ser reduzida a um conjunto de normas e prescrições; sua missão é explicar a moral efetiva e, neste sentido, pode influir na própria moral.

Assim sendo, enquanto moral é o conjunto de 'valores' preservados numa determinada cultura, podendo ser, portanto, relativa a uma cultura e não a outras, a ética é a determinação de fundamentar a ação em bases não relativistas.

O objetivo de nosso trabalho é favorecer um repensar sobre as práticas pedagógicas no cotidiano das salas de aula, onde os professores da Educação Básica, através dos saberes docentes, transformem o espaço da sala de aula tradicional num espaço diferente, onde os alunos possam desenvolver seus próprios meios e recursos de aprendizado de valores, descobrindo e vivenciando competências e habilidades.

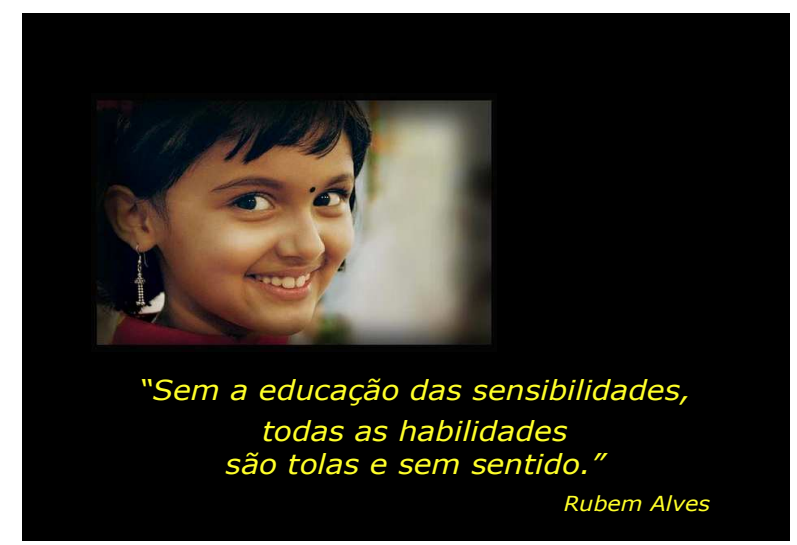

Fig. 4: Competências filosóficas

Tomando por base a afirmativa de que o homem é o único ser ético, realizaremos um trabalho de exercício das competências filosóficas, a partir da leitura e discussão dos principais conceitos éticos, para elucidar o papel do homem e desenvolver no participante uma compreensão melhor de si mesmo, enquanto ser integral, social, agente da história e de sua própria história e de suas possibilidades criativas, a partir do foco no processo de conhecimento da ética e nas relações que se estabelecem, tanto na dimensão prática do cotidiano, quanto na dimensão de salas de aula.

Em outras palavras, se a ética exige um sujeito autônomo, a ideia do dever não introduz a heteronomia, isto é, o domínio da vontade e da consciência humana por um 
poder estranho ao homem, mas sim a autonomia, no saber decidir e fazer na sua relação com o outro.

Cartolano (1998, p.30) apud Rodrigues (2006), afirma a importância de uma formação de professores onde haja comprometimento com a função social de educar todos os alunos, pois "os educadores de hoje não podem esquivar-se dessa realidade social e, muito menos, perder de vista a viabilidade histórica de um projeto de transformação do real".

Partindo da premissa de que o professor é aquele que ensina alguma coisa a alguém, os saberes docentes constituem-se como essenciais para as atividades docentes e fundamentais para a configuração da identidade profissional do educador. O tema saberes docentes tem sido foco de muitos pesquisadores, nos últimos anos, que buscam conhecer de que forma são apropriados, modificados e mobilizados na prática pedagógica dos professores. Os estudos consideram que a constituição desses saberes é o ponto de partida dos projetos de formação dos educadores, valorizando-os como produtores de saberes (ZIBETTI; SOUZA, 2007).

Tardif define o saber docente "[...] Como um saber plural, formado pelo amálgama, mais ou menos coerente, de saberes oriundos da formação profissional e de saberes disciplinares, curriculares e experiências" (TARDIF apud ALMEIDA, 2007, p. 36). tante

Para Perrenoud (2001, p.19) é impor-

fazer que cada aprendiz vivencie, tão frequentemente quanto possível, situações fecundas de aprendizagem. Para executar essa ideia tão simples é preciso mudar profundamente a escola. Acrescentemos de imediato que adaptar a ação pedagógica ao aprendiz não é, no entan- to, nem renunciar a instrui-lo, nem abdicar dos objetivos essenciais.

Diante desta contextualização, propomos o desenvolvimento de uma práxis diferente para professores e estudantes do Ensino Médio. Práxis esta que exigirá um fazer pedagógico diferenciado, que hoje pouco se observa nas nossas salas de aula, que investem, ainda, no antigo modelo tradicional do professor como "dono do saber". Este novo fazer pedagógico é diferenciado, uma vez que contemplará todos os sujeitos no processo de ensino e aprendizagem, independentemente dos papéis que exercem, para que dialoguem através da teoria e prática.

Enquanto componente curricular no Ensino Médio, o ensino da Filosofia tem como objetivo formar educandos que demonstrem o domínio dos conhecimentos de Filosofia necessários ao exercício da cidadania. Assim sendo, o compromisso e o diálogo com o aluno se tornam fundamentais para o "ensinar a aprender". O jovem deixa de ser apenas espectador na sala de aula e passa a ser sujeito ativo no seu processo de aprendizagem.

No ensino da Filosofia, dialogar entre teoria e prática, nas salas de aula, implica que as informações conceituais sobre a ética e a moral se articulem e complementem, através da sua aplicabilidade, em discussões de vivências do dia a dia e de outros recursos, tais como filmes paradidáticos, livros, charges, notícias em divulgadas pela mídia etc.

Cabe ao professor levar para as salas de aula atividades capazes de favorecer aprendizagens significativas. Cada aprendiz, respeitando sua individualidade e as diversidades sociais, deverá efetivamente construir conhecimentos, saberes para a vida, para que seja um indivíduo participativo em sua 
comunidade, consciente da sua responsabilidade na construção de uma sociedade mais justa e um mundo de paz.

Entendemos que é preciso repensar a escola e a prática dentro das nossas salas de aula, para atendermos às demandas impostas pela sociedade contemporânea, onde os avanços tecnológicos provocam transformações numa velocidade cada vez maior. A escola e consequentemente suas salas de aula precisam assumir uma pedagogia da autonomia capaz de transformar o cotidiano escolar dando-lhe o dinamismo do mundo atual.

\section{REFERÊNCIAS BIBLIOGRÁFICAS:}

ALVES, R. Educação das sensibilidades. Disponível em: entrecanetaeopapel.blogspot.com/2010/01/educação-dassensibilidades.html. Acesso: 30 agosto 2011.

ARANHA, Maria Lúcia Arruda. Filosofando: introdução à Filosofia. $4^{a}$ ed. rev. São Paulo: Moderna, 2009.

BOSSA, N.A. Fracasso Escolar: um olhar psicopedagógico. Porto Alegre: Artemed, 2002.

BRASIL. Lei n 9394, de 20 de dezembro de 1996. Estabelece as diretrizes e bases da educação nacional. Diário Oficial [da] República Federativa do Brasil, Brasília, DF. 23 dez. 1996. Cortesia da Editora do Brasil.

Ministério da Educação, Secretaria de Educação Média e Tecnológica. Parâmetros curriculares nacionais: ensino médio. Brasília: Ministério da Educação, 1999.

Ciências Humanas e suas tecnologias. Secretaria de Educação Média e Tecnológica. PCN + Ensino Médio: Orientações Educacionais complementares aos
Parâmetros Curriculares Nacionais. Brasília: MEC, SEMTEC, 2002.

CHAUÍ, M. Convite à Filosofia. São Paulo: Ática, 2006.

MARCHESI, A. O que será de nós, os maus alunos? Trad. Ernani Rosa. Porto Alegre: Artmed, 2006.

OLIVEIRA, M. A. Correntes Fundamentais da Ética Contemporânea. Petrópolis: Ed. Vozes, 2001.

PERRENOUD, P. Pedagogia diferenciada: das intenções à ação. Porto Alegre: Artmed, 2001.

RODRIGUES, D. (Org.). Inclusão e educação: doze olhares sobre a educação inclusiva. São Paulo: Summus, 2006.

SOUZA, A. B. Ética e Cidadania na Educação. Rio de Janeiro: Paulos, 2010.

TARDIF, M. Saberes docentes e formação profissional. Petrópolis: Vozes, 2002.

VÁSQUES, A. S. Ética. Rio de Janeiro: Civilização Brasileira, 2008.

ZIBETTI, T.; SOUZA, M.L.R. et al. Apropriação e mobilização de saberes na prática pedagógica: contribuição para a formação de professores. Educação e Pesquisa. 2007. n. 33 (maio-agosto) Disponível em: <http://redalyc.uaemex.mx/redalyc/src/inici o/ArtPdfRed.jsp?iCve=29833205 > ISSN 1517-9702. Acesso em: 20 janeiro 2011. 